\title{
Composição tecidual da carcaça e perfil de ácidos graxos da carne de cordeiros terminados a pasto ou em confinamento ${ }^{1}$
}

\author{
Maria Angela Machado Fernandes ${ }^{2}$, Alda Lúcia Gomes Monteiro², César Henrique Espírito \\ Candal Poli ${ }^{3}$, Carina Simionato de Barros ${ }^{2}$, Rodrigo de Almeida ${ }^{2}$, Ticiany Maria Dias Ribeiro 4 \\ ${ }^{1}$ Apoio do CNPq - Auxílio financeiro à pesquisa. \\ 2 Pós-Graduação em Ciências Veterinárias da UFPR. Rua dos Funcionários, 1540, Cabral, 800035-050, Curitiba, PR. \\ ${ }^{3}$ Departamento de Zootecnia, UFRGS. \\ ${ }^{4}$ Doutoranda do Curso de Pós-Graduação em Zootecnia, UNESP/Botucatu.
}

RESUMO - Objetivou-se avaliar a composição tecidual do lombo e do pernil e o perfil de ácidos graxos da carne de cordeiros em quatro sistemas de terminação: 1) cordeiros desmamados com média de 40 dias e mantidos em pasto de azevém até o abate; 2) cordeiros com suas mães na mesma pastagem até o abate; 3) idem ao 2), porém com suplementação diária a $1 \%$ do PV em creep feeding; 4) cordeiros desmamados aos 40 dias e confinados, recebendo silagem de milho e concentrado ad libitum. O delineamento experimental foi inteiramente casualizado com quatro sistemas de terminação e três repetições. Os cordeiros foram abatidos com $32 \mathrm{~kg}$ de peso vivo. Os lombos e pernis direitos foram utilizados para determinação da composição tecidual e os lombos esquerdos, para análise do perfil de ácidos graxos. No lombo esquerdo foram mensurados: comprimento e profundidade máxima do músculo; espessura mínima e máxima de gordura de cobertura e área de olho-delombo. Os cordeiros desmamados terminados a pasto apresentaram menor deposição de gordura na carcaça e índice de musculosidade do pernil. O desenvolvimento muscular e a deposição de gordura nos cordeiros terminados ao pé da mãe, com ou sem suplementação, foram semelhantes aos observados nos cordeiros desmamados e terminados em confinamento. Cordeiros em creep feeding apresentaram mais ácidos graxos na carne que cordeiros desmamados a pasto. Os sistemas de terminação influenciam a composição tecidual, mas não afetam o perfil de ácidos graxos da carne para consumo humano.

Palavras-chave: gordura, músculo, qualidade da carne, pasto de azevém

\section{Tissue composition of carcass and meat fatty acids profile of lambs finished on pasture and feedlot systems}

\begin{abstract}
The objective of this study was to evaluate tissue composition of loin and leg and fatty acids profile of the meat of lambs in four finishing systems: (1) lambs weaned around 40 days of age and kept in ryegrass pastures until slaughter; (2) lambs kept with their dams in the same pasture until slaughter; (3) same treatment of (2), but daily supplemented with $1 \%$ of the body weight in creep feeding; (4) lambs weaned at 40 days of age and confined, fed corn silage and concentrate ad libitum. It was used a complete random experimental design with four finishing systems and three replications. Lambs were slaughtered at body weight of $32 \mathrm{~kg}$. Loins and right legs were used for determining tissue composition and the left loins were used for analyzing fatty acid profile. Length and maximal deep of the muscle, minimal and maximal thickness of backfat and loin eye area were measured on the left legs. Pasture finished weaned lambs showed lower fat deposition on the carcass and leg muscularity index. Muscle development and fat deposition on finished weaned lamb with or without supplementation were similar to the ones observed on feedlot finished weaned lambs. Lambs in creep feeding showed more fatty acids in the meat than pasture weaned lambs. Finishing systems influence tissue composition but they do not affect fatty acid profile in meat for human consumption.
\end{abstract}

Key Words: fat, meat quality, muscle, ryegrass pasture

\section{Introdução}

Mudanças decorrentes da estabilidade econômica, melhoria do poder aquisitivo e a preocupação com saúde vêm fazendo o consumidor atual mais exigente (Luchiari
Filho, 2000) no consumo de alimentos. Tem-se verificado interesse dos consumidores no efeito benéfico de determinados alimentos, que além de satisfazerem as necessidades nutritivas básicas forneçam um benefício fisiológico adicional (Hasler, 1998). Isso tem estimulado a

Recebido em 29/8/2008 e aprovado em 9/7/2009.

Correspondências devem ser enviadas para: angela.ufpr@gmail.com 
indústria e os pesquisadores da ciência da carne a procurarem soluções para diminuir o teor de ácidos graxos saturados e aumentar o de poliinsaturados.

Por meio da nutrição dos animais é possível modificar o conteúdo dos diferentes ácidos graxos na musculatura e alterar as relações entre eles, tornando a carne mais saudável (Andrade et al., 2001). Santos-Silva et al. (2002) concluíram que a gordura de cordeiros criados a pasto foi mais adequada que a proveniente de cordeiros alimentados com concentrado, pela maior quantidade de ácidos graxos poliinsaturados n-3, maior concentração de ácido linoleico conjugado e menor relação n-6:n-3. Díaz et al (2002) afirmaram que o pasto contém alto nível de ácido linolênico, precursor da série de ácidos graxos n-3, enquanto que os concentrados em geral são ricos em ácido linoleico, precursor dos n-6.

De acordo com Bueno et al. (2000), as carcaças devem apresentar elevada porcentagem de músculos, cobertura de gordura subcutânea uniforme e teor de gordura adequado ao mercado consumidor. Altos teores de gordura depreciam o valor comercial das carcaças, porém faz-se necessária certa deposição de tecido adiposo determinante de características sensoriais da carne e para prevenir maiores perdas de água durante sua conservação (Osório et al., 2002).

O efeito nutricional sobre a composição física da carcaça tem sido bastante estudado e tem-se verificado que animais com melhor regime alimentar apresentam carcaças de melhor qualidade, evidenciadas por maior desenvolvimento muscular, boa deposição de gordura e menor proporção de ossos (Diaz et al., 2002; Fernandes et al., 2008; Santos-Silva et al., 2002).

A composição tecidual baseia-se na dissecação da carcaça, separando-se a gordura, a carne magra e o osso (Sañudo \& Sierra, 1986). A dissecação de toda a carcaça, ou de metade apenas, só se justifica em casos especiais, por ser onerosa, muito trabalhosa e lenta. O mais comum é a desossa dos principais cortes comerciais, ou daqueles que sejam representativos da composição da carcaça. Para isso, pode-se utilizar, com certa precisão, a composição tecidual de partes da composição regional, já que existe uma relação significativa entre elas (Osório et al., 2002).

Neste trabalho objetivou-se avaliar a influência de quatro sistemas de terminação na composição tecidual da carcaça e no perfil de ácidos graxos da carne de cordeiros.

\section{Material e Métodos}

O experimento foi realizado entre 5 de agosto de 2004 e 7 de janeiro de 2005 no Laboratório de Produção e Pesquisa de Ovinos e Caprinos (LAPOC), na Fazenda Experimental da Universidade Federal do Paraná, localizada na região metropolitana de Curitiba, tendo como coordenadas geográficas $25^{\circ} 25^{\prime}$ Sul e $49^{\circ} 8^{\prime}$ Oeste e 915 m de altitude.

Foram utilizados 36 cordeiros da raça Suffolk, machos inteiros, com média de 15,5 kg de peso vivo. O delineamento experimental foi inteiramente casualizado com quatro sistemas de terminação e três repetições (piquetes ou baias). Foram avaliados três cordeiros por repetição, sendo um macho de parto simples e dois de parto gemelar, totalizando nove cordeiros por tratamento.

A partir dos 40 dias de idade média até o abate, os animais foram submetidos aos seguintes sistemas de alimentação: (1) desmamados e mantidos em pasto de azevém (Lolium multiflorum Lam.); (2) mantidos com as mães em pasto de azevém; (3) idem ao 2 mais suplementação diária com concentrado a $1 \%$ do peso corporal em creep feeding; (4) confinamento com silagem de milho e concentrado ad libitum (70\% de silagem de milho e 30\% de ração farelada).

Em pasto, os animais foram distribuídos em seis piquetes de 0,35 ha, para os cordeiros com ovelhas, e três piquetes de 0,15 há, para os cordeiros desmamados. O método de utilização da pastagem foi o de lotação contínua com carga animal variável, com três cordeiros testes e número variável de reguladores em cada piquete. Os cordeiros testes permaneceram nos piquetes durante todo o período de avaliação até o abate. Os reguladores foram usados para ajustar a carga animal pela técnica “put and take” (Mott \& Lucas, 1952) a cada 14 dias pela disponibilidade de massa de folhas em $1000 \mathrm{~kg}$ MS/ha em todos os sistemas de terminação.

No sistema confinado, os cordeiros foram desmamados e confinados em baias coletivas cobertas, em piso ripado e suspenso. A dieta era fornecida ad libitum com sobra diária de $10 \%$ para não limitar o consumo, formulada segundo NRC (1985) para atender as exigências de cordeiros com potencial de crescimento rápido. Os ingredientes do concentrado foram: $51 \%$ de grão de milho; $31 \%$ de farelo de soja; $15 \%$ de farelo de trigo; 0,5\% de calcário calcítico; 0,5\% de sal comum e $2 \%$ de núcleo mineral (níveis de garantia por kg: 120 g de cálcio, 87 g de fósforo, 147 g de sódio, 18 g de enxofre, cobre $590 \mathrm{mg}$, cobalto $40 \mathrm{mg}$, cromo $20 \mathrm{mg}$, ferro $1800 \mathrm{mg}$, iodo $80 \mathrm{mg}$, manganês 1300 mg, selênio 15 mg, zinco 3800 mg, molibdênio 300 mg, flúor máximo 870 mg).

A qualidade da pastagem foi determinada em amostra colhida por simulação do pastejo (Euclides et al., 1992). As análises bromatológicas foram realizadas no Laboratório de Nutrição Animal da UFPR, de acordo com Silva (1990).

Os cordeiros foram abatidos com peso vivo individual de $32 \mathrm{~kg}$. Na véspera do abate, os animais permaneceram em dieta apenas hídrica por 16 horas. A insensibilização foi feita por eletronarcose com descarga elétrica de $220 \mathrm{~V}$ por 
oito segundos e a sangria, pela secção das veias jugulares e artérias carótidas. Após o toalete, as carcaças foram penduradas pelas articulações tarso-metatarsianas em ganchos com abertura de $17 \mathrm{~cm}$. e foram avaliadas visualmente quanto à conformação de acordo com ColomerRocher et al. (1988), atribuindo-se valores de um a cinco, segundo a distribuição dos planos musculares. O estado de engorduramento foi avaliado pela distribuição harmônica da gordura na carcaça, também pontuadas de um a cinco, desde extremamente magra até extremamente gorda, com escala a cada 0,5, conforme Cañeque et al. (1992). Em seguida as carcaças foram resfriadas em câmara fria a $5^{\circ} \mathrm{C}$ por 24 horas. Após o resfriamento, foram divididas longitudinalmente, e a meia-carcaça esquerda foi seccionada em sete regiões anatômicas, conforme Colomer-Rocher \& Espejo (1988): lombo, paleta, perna, costela, costela descoberta, pescoço e baixos.

Na porção dorsal do músculo longissimus lumborum no lombo esquerdo, na altura da $13^{\underline{a}}$ vértebra torácica, foram efetuadas as seguintes mensurações: medida A (comprimento máximo do músculo), medida B (profundidade máxima do músculo), medida $C$ (espessura mínima de gordura de cobertura sobre o músculo) e medida J (espessura máxima de gordura de cobertura sobre o perfil do lombo). O perfil do músculo longissimus lumborum foi traçado em papel vegetal para posterior obtenção de área de lombo. Esta foi calculada por meio de área conhecida $\left(4 \mathrm{~cm}^{2}\right)$ que foi pesada, e posteriormente pesou-se o perfil do lombo, obtendo, por regra de três, a sua área.

Os lombos e pernis direitos foram identificados, embalados e congelados para posterior dissecação. Antes de serem dissecados, os cortes foram descongelados a $10^{\circ} \mathrm{C}$, em geladeira, por 8 horas, dentro dos sacos plásticos.

Os lombos foram dissecados com o auxílio de bisturi. A gordura subcutânea total foi removida e pesada. Então, foram dissecados o músculo longissimus lumborum, a gordura intermuscular e o osso. Tecidos não identificados compostos por tendões, glândulas, fáscias, nervos e vasos sanguíneos foram pesados juntos e denominados outros componentes. Após a dissecação, todos os componentes foram pesados separadamente. A gordura intermuscular foi pesada separadamente e em conjunto com a gordura subcutânea que resultou no peso de gordura total.

Os pernis foram dissecados segundo a metodologia de Brown \& Willians (1979). Mediu-se o comprimento do fêmur (cm) e o índice de musculosidade da perna foi calculado pela fórmula descrita por Purchas et al. (1991): índice de musculosidade da perna $=I M P=\frac{\sqrt{P 5 M / C F}}{C F}$, em que P5M é o peso ( $\mathrm{g}$ ) dos cinco músculos que envolvem o fêmur (bíceps femoral, semitendinoso, semimembranoso, adutor e quadríceps femoral) e CF é o comprimento do fêmur (cm).

Para análise de perfil de ácidos graxos, foram coletadas amostras do lombo inteiro, referentes à meia-carcaça a esquerda, sem porção de gordura de cobertura localizada nessa região. A análise da composição em ácidos graxos foi realizada por meio de cromatografia gás-líquido - os ésteres de ácidos graxos analisados em cromatógrafo Shimadzu com coluna capilar de sílica fundida, segundo metodologia de Hartman \& Lago (1973), no Centro de Pesquisas e Processamento de Alimentos (CEPPA) da UFPR.

Os dados obtidos foram submetidos à análise de variância utilizando-se o modelo $\mathrm{Y}_{\mathrm{ij}}=\mu+\mathrm{T}_{\mathrm{i}}+\mathrm{e}_{\mathrm{ij}}$; em que: $\mathrm{Y}_{\mathrm{ij}}=$ valor observado da variável estudada no indivíduo $\mathrm{j}$ recebendo o tratamento $\mathrm{i} ; \mu=$ média geral; $\mathrm{T}_{\mathrm{i}}=$ efeito do tratamento $\mathrm{i} ; \mathrm{e}_{\mathrm{ij}}=$ erro aleatório associado a cada observação $\mathrm{Y}_{\mathrm{ij}}$. Foram feitos os testes de médias, com probabilidade de 5\% (teste de Tukey). As correlações entre variáveis foram analisadas pela Correlação Simples de Pearson. A análise estatística foi realizada com programa estatístico SAS (2001).

\section{Resultados e Discussão}

Os músculos de maturidade tardia são citados pela representatividade do desenvolvimento e tamanho do tecido muscular; assim, o longissimus lumborum é o mais

Tabela 1 - Composição química do concentrado, da silagem de milho e do pasto de azevém utilizados nos sistemas de terminação (\% matéria seca)

\begin{tabular}{|c|c|c|c|}
\hline Item & Concentrado $^{1}$ & Silagem de milho & Pasto de azevém \\
\hline Matéria seca & 86,59 & 25,40 & 18,00 \\
\hline Proteína bruta & 20,48 & 8,50 & 19,75 \\
\hline Energia metabolizável (Mcal/kg) & 2,70 & 2,41 & 2,64 \\
\hline Nutrientes digestíveis totais ${ }^{3}$ & 74,70 & 66,9 & 73,17 \\
\hline Fibra em detergente neutro & 31,63 & 55,8 & 56,91 \\
\hline Fibra em detergente ácido & 5,86 & 32,2 & 25,25 \\
\hline Cálcio & 1,13 & 0,55 & 0,72 \\
\hline Fósforo & 0,80 & 0,07 & 0,28 \\
\hline
\end{tabular}

${ }^{1}$ Concentrado utilizado para o sistema com o creep feeding e confinamento.

${ }^{2}$ O NDT foi calculado segundo Kearl (1982). 
Tabela 2 - Mensurações do músculo longissimus lumborum de cordeiros produzidos em quatro sistemas de terminação

\begin{tabular}{|c|c|c|c|c|c|}
\hline & \multicolumn{4}{|c|}{ Sistema de terminação } & \multirow{2}{*}{$\begin{array}{l}\text { Erro-padrão } \\
\text { da média }\end{array}$} \\
\hline & Pastagem & $\begin{array}{l}\text { Pastagem } \\
\text { mãe }\end{array}$ & $\begin{array}{c}\text { Pastagem }+ \text { creep } \\
\text { feeding }+ \text { mãe }\end{array}$ & Confinamento & \\
\hline Comprimento máximo (cm) & 5,67 & 6,01 & 6,43 & 5,82 & 0,35 \\
\hline Profundidade máxima (cm) & 2,27 & 2,75 & 2,78 & 2,64 & 0,10 \\
\hline Espessura mínima de gordura de cobertura (mm) & $0,71 b$ & $1,93 \mathrm{a}$ & $2,60 \mathrm{a}$ & 2,68 a & 0,27 \\
\hline Espessura máxima de gordura de cobertura $(\mathrm{mm})$ & $0,81 \mathrm{c}$ & $3,79 \mathrm{~b}$ & $7,05 a$ & $6,11 \mathrm{a}$ & 0,69 \\
\hline Área de olho-de-lombo $\left(\mathrm{cm}^{2}\right)$ & 10,62 & 11,42 & 12,35 & 11,27 & 0,30 \\
\hline
\end{tabular}

Médias seguidas de letras diferentes na mesma linha diferem $(\mathrm{P}<0,05)$ pelo teste Tukey.

indicado, pois, além do amadurecimento tardio, é de fácil mensuração (Sainz, 1996). Os sistemas de terminação não tiveram efeito $(\mathrm{P}>0,05)$ sobre comprimento, a profundidade máxima e a área de lombo e, não afetaram, portanto, o desenvolvimento muscular dos cordeiros (Tabela 2).

Fernandes et al. (2008), trabalhando com os mesmos sistemas de terminação em pasto de verão (tifton-85), também não observaram efeito do sistema de terminação sobre o comprimento $(5,25 \mathrm{~cm})$ e profundidade do músculo $(2,78 \mathrm{~cm})$ e área de lombo $\left(13,08 \mathrm{~cm}^{2}\right)$ dos cordeiros.

Cordeiros com dieta exclusivamente em pasto apresentaram menor $(\mathrm{P}<0,05)$ espessura mínima e máxima de gordura de cobertura no lombo. Animais terminados ao pé da mãe sem suplementação apresentaram espessura máxima de gordura menor $(\mathrm{P}<0,05)$ que os terminados em creep feeding e desmamados confinados.

Para ovinos, ainda não há valor mínimo para gordura de cobertura que determine que, a partir deste, há excesso ou baixa deposição de gordura. Siqueira e Fernandes (2000) citaram a espessura mínima de gordura de cobertura de 1,4 mm para animais abatidos aos $32 \mathrm{~kg}$. Nesse trabalho, apenas os cordeiros desmamados em pasto apresentaram gordura de cobertura inferior a tal valor $(0,81 \mathrm{~mm})$.
Observa-se que os sistemas de terminação não afetaram o desenvolvimento ósseo, peso de outros tecidos (tendões, glândulas, fáscias, nervos e vasos sanguíneos) e a relação músculo:osso (Tabelas 3 e 4). No entanto, a alimentação afetou tanto o desenvolvimento muscular do lombo quanto a deposição de gordura na carcaça.

Os animais que foram desmamados e terminados em azevém apresentaram menor $(\mathrm{P}<0,05)$ peso total de lombo e pernil em relação aos demais, apesar de abatidos com o mesmo peso vivo. Cordeiros suplementados mantidos com suas mães tiveram maior $(\mathrm{P}<0,05)$ peso de lombo comparados aos que também permaneceram com as mães, sem suplementação; e ambos foram semelhantes $(\mathrm{P}>0,05)$ aos confinados.

Cordeiros desmamados e terminados em pasto tiveram peso total de músculo do lombo inferior $(\mathrm{P}<0,05)$ ao dos cordeiros terminados em creep feeding, e também dos desmamados terminados em confinamento. Ou seja, animais que foram terminados com dieta exclusivamente em pasto apresentaram menor desenvolvimento muscular comparados aos demais.

Houve correlação significativa $(\mathrm{P}<0,01)$ positiva $(\mathrm{r}=0,95)$ entre peso total de músculo do lombo e ganho de peso

Tabela 3 - Composição tecidual do lombo de cordeiros produzidos em quatro sistemas de terminação

\begin{tabular}{|c|c|c|c|c|c|}
\hline & \multicolumn{4}{|c|}{ Sistema de terminação } & \multirow{2}{*}{$\begin{array}{c}\text { Erro-padrão } \\
\text { da média }\end{array}$} \\
\hline & Pastagem & $\begin{array}{l}\text { Pastagem }+ \\
\text { mãe }\end{array}$ & $\begin{array}{c}\text { Pastagem }+ \text { creep } \\
\text { feeding }+ \text { mãe }\end{array}$ & Confinamento & \\
\hline Peso do lombo (g) & $607,5 \mathrm{c}$ & $785,0 \mathrm{~b}$ & $893,8 a$ & $809,4 \mathrm{ab}$ & 30,10 \\
\hline Músculo (g) & $378,7 b$ & $424,4 \mathrm{ab}$ & $452,7 \mathrm{a}$ & $451,6 \mathrm{a}$ & 14,38 \\
\hline \multicolumn{6}{|l|}{ Gordura (g) } \\
\hline Subcutânea (g) & $28,7 b$ & $79,4 a$ & $85,5 a$ & $96,6 a$ & 9,62 \\
\hline Intermuscular (g) & $22,5 c$ & $74,4 \mathrm{~b}$ & $114,7 \mathrm{a}$ & $74,1 \mathrm{~b}$ & 12,16 \\
\hline Total (g) & $51,2 b$ & $153,8 \mathrm{a}$ & $200,2 a$ & $170,8 \mathrm{a}$ & 16,58 \\
\hline Osso (g) & 122,5 & 130,0 & 138,6 & 123,0 & 11,15 \\
\hline Outros tecidos (g) & 32,5 & 30,5 & 44,4 & 31,1 & 4,68 \\
\hline Músculo:gordura (g) & $7,37 \mathrm{a}$ & $2,91 b$ & $2,27 b$ & $2,65 b$ & 0,28 \\
\hline Músculo:osso (g) & 3,18 & 3,27 & 3,31 & 3,71 & 0,35 \\
\hline Músculo (g) & $64,56 a$ & $57,64 \mathrm{ab}$ & $53,59 b$ & $58,22 \mathrm{ab}$ & 2,21 \\
\hline Gordura (g) & $8,75 b$ & $20,57 \mathrm{a}$ & $23,64 a$ & $22,05 \mathrm{a}$ & 1,55 \\
\hline
\end{tabular}

Médias seguidas de letras diferentes na mesma linha diferem $(\mathrm{P}<0,05)$ pelo teste Tukey. 
Tabela 4 - Composição tecidual do pernil (g) de cordeiros produzidos em quatro sistemas de terminação

\begin{tabular}{|c|c|c|c|c|c|}
\hline & \multicolumn{4}{|c|}{ Sistema de terminação } & \multirow{2}{*}{$\begin{array}{l}\text { Erro-padrão } \\
\text { da média }\end{array}$} \\
\hline & Pastagem & $\begin{array}{l}\text { Pastagem } \\
\text { mãe }\end{array}$ & $\begin{array}{c}\text { Pastagem }+ \text { creep } \\
\text { feeding }+ \text { mãe }\end{array}$ & Confinamento & \\
\hline Peso total & $2185,0 b$ & $2341,7 \mathrm{ab}$ & $2357,5 a$ & $2381,1 \mathrm{a}$ & 34,06 \\
\hline Músculo total & 1288,7 & 1382,5 & 1330,8 & 1382,5 & 23,42 \\
\hline Semimembranoso & $186,2 b$ & $210,0 \mathrm{a}$ & $204,4 \mathrm{ab}$ & $207,8 \mathrm{ab}$ & 4,27 \\
\hline Semitendinoso & $68,7 c$ & $81,7 \mathrm{a}$ & $78,1 \mathrm{a}$ & $84,7 \mathrm{a}$ & 1,69 \\
\hline Bíceps femoral & 195,0 & 220,8 & 209,7 & 228,6 & 10,43 \\
\hline Quadríceps femoral & 261,2 & 282,5 & 269,4 & 291,4 & 6,74 \\
\hline Adutor & 97,5 & 90,0 & 93,1 & 87,8 & 4,74 \\
\hline Outros músculos & 485,8 & 497,5 & 476,1 & 482,2 & 12,72 \\
\hline \multicolumn{6}{|l|}{ Gordura } \\
\hline Subcutânea & $55,0 \mathrm{c}$ & $121,7 \mathrm{~b}$ & $160,0 \mathrm{a}$ & $152,2 \mathrm{a}$ & 9,04 \\
\hline Intermuscular & 92,5 & 97,5 & 136,4 & 90,3 & 14,05 \\
\hline Total & $147,5 c$ & $219,2 b$ & $296,4 a$ & $242,5 \mathrm{ab}$ & 20,66 \\
\hline Osso total & 485,0 & 456,7 & 439,7 & 443,3 & 10,34 \\
\hline Fêmur & 148,7 & 141,7 & 140,6 & 141,7 & 3,56 \\
\hline Comprimento do fêmur & 17,4 & 16,8 & 16,6 & 17,0 & 0,19 \\
\hline Músculo: gordura & $8,7 a$ & $6,52 b$ & $4,53 c$ & $5,71 \mathrm{bc}$ & 0,48 \\
\hline Índice de musculosidade ${ }^{1}$ & $0,39 b$ & $0,43 a$ & $0,43 a$ & $0,43 a$ & 0,01 \\
\hline Músculo (\%) & 67,15 & 67,20 & 64,40 & 66,82 & 0,96 \\
\hline Gordura (\%) & 7,99c & $10,56 \mathrm{bc}$ & $14,32 \mathrm{a}$ & $11,41 b$ & 0,78 \\
\hline Osso (\%) & $24,89 a$ & $22,23 b$ & $21,27 b$ & $21,44 b$ & 0,50 \\
\hline
\end{tabular}

Médias seguidas por letras distintas nas linhas diferem $(\mathrm{P}<0,05)$ entre si pelo teste Tukey.

${ }^{1}$ Raiz quadrada [peso dos cinco músculos, em g]/[comprimento do fêmur, em c]/[comprimento do fêmur, em cm] (Purchas et al., 1991).

médio diário. Ribeiro (2009b) relatou desempenho inferior desses cordeiros desmamados em pasto $(0,120 \mathrm{~kg} / \mathrm{dia})$ quando comparados aos terminados sem desmame com $(0,303 \mathrm{~kg} /$ dia $)$ ou sem $(0,294 \mathrm{~kg} /$ dia $)$ suplementação e aos confinados (0,338 kg/dia). Esse menor desempenho pode ter sido causado, provavelmente, pela incapacidade dos animais ingerirem volume suficiente de pasto para atenderem às exigências nutricionais nessa fase.

Além disso, é preciso considerar o estresse causado pelo desmame associado à ausência de ingestão do leite materno. De acordo com Carvalho (2004), em cordeiros de $25 \mathrm{~kg}$, o leite ainda é responsável por 25\% da energia ingerida, além de que a exigência em aminoácidos é bastante elevada, o que faz do leite alimento fundamental ao cordeiro nessa etapa, sendo que o “desmame antecipado” é um desafio nutricional ao cordeiro. No presente trabalho, embora a forragem de azevém fosse de boa qualidade (Tabela 1) e disponibilidade (ao redor de $12 \%$ de oferta de forragem), as exigências para o desenvolvimento e crescimento dos cordeiros desmamados aos $15,5 \mathrm{~kg}$ de peso vivo e terminados em pasto possam não ter sido atendidas ou houve ingestão insuficiente de forragem. Isso resultou em limitação de desenvolvimento de tecidos corporais.

Não houve efeito do sistema de terminação $(\mathrm{P}>0,05)$ sobre o peso total de músculo de pernil, bíceps femoral, quadríceps femoral, adutor, outros músculos e percentual de músculo (Tabela 4). No entanto, entre os principais músculos do pernil, cordeiros desmamados terminados em pasto apresentaram menor peso $(\mathrm{P}<0,05)$ dos músculos semimembranoso e semitendinoso do que os demais cordeiros.

A gordura apresenta importante papel na qualidade e na conservação da carne — os depósitos de gordura intermuscular, subcutâneo e intramuscular influem diretamente na maciez e suculência, uma vez que com o aumento das gorduras intermuscular e intramuscular ocorre maior sensação destas no ato mastigatório; e, com aumento da gordura subcutânea, diminui o risco de encurtamento pelo frio (Osório et al., 2002).

Os sistemas de terminação não tiveram efeito $(\mathrm{P}>0,05)$ sobre a deposição de gordura intermuscular do pernil; no entanto, cordeiros desmamados terminados em pasto, abatidos aos 158 dias de idade, apresentaram menor $(\mathrm{P}<0,05)$ peso de gordura intermuscular no lombo e de gorduras subcutânea, total e percentuais de gordura do lombo e pernil. Cordeiros em creep feeding, abatidos aos 106 dias de idade, apresentaram pesos de gordura subcutânea e total do pernil semelhantes $(\mathrm{P}>0,05)$ aos cordeiros confinados, abatidos aos 96 dias de idade. Já, a gordura no pernil destes últimos foi superior $(\mathrm{P}<0,05)$ à dos que não estavam em creep feeding, abatidos aos 105 dias de idade.

É conveniente lembrar que a gordura influencia também o valor comercial das carcaças — adequado nível acarreta em aumento no valor, enquanto o excesso leva à sua depreciação (Osório et al., 2002). Segundo Huidobro 
\& Cañeque (1994), esta tem papel decisivo no comportamento da maioria dos agentes da cadeia produtiva, visto que a gordura é um tecido de deposição tardia e que ocorre com elevado consumo de energia, o que torna alto o custo da alimentação, principalmente em quantidade elevada de concentrado.

Segundo Diaz et al. (2002), cordeiros terminados em pasto, geralmente, têm menos gordura que animais terminados em confinamento; isso porque animais em pastejo têm maiores exigências de energia devido ao aumento do metabolismo basal associado ao pastejo.

Os cordeiros terminados em pasto sem desmame, com ou sem suplementação, apresentaram pesos de músculo e de gordura da carcaça e espessura de gordura sobre o lombo semelhantes aos dos cordeiros confinados e superior aos dos desmamados terminados exclusivamente a pasto. Portanto, a mãe e o leite materno foram fundamentais para que as exigências nutricionais para o desenvolvimento muscular e adiposo da carcaça dos cordeiros em pasto fossem atendidas. Possivelmente, essa diferença na deposição de gordura entre os cordeiros com suas mães e os desmamados com dieta em pasto possa também ser explicada pela incapacidade destes em ingerirem quantidade suficiente de pasto para compensar a supressão do leite, que possui maior digestibilidade e eficiência de utilização de energia metabolizável (Cañeque et al., 1992).

O confinamento de cordeiros desmamados com dieta de boa qualidade demonstrou ser uma alternativa para compensar a falta de ingestão do leite materno. Talvez, uma das alternativas fosse abater os cordeiros desmamados terminados com dieta exclusivamente a pasto com maior peso de abate, para obter acabamento da carcaça próximo ao dos demais.

Rosa et al. (2002) e Gonzaga Neto et al. (2006) observaram maiores proporções de gordura nas carcaças de cordeiros mais pesados e alimentados com dietas mais energéticas. No presente trabalho, a presença da mãe juntamente com a suplementação concentrada em creep feeding a 1\% do PV proporcionou aumento na deposição de gordura dos cordeiros.

Sañudo \& Sierra (1986) afirmaram que a melhor conformação pode estar atrelada a maiores teores de tecido adiposo. A conformação das carcaças apresentou correlação $(\mathrm{P}<0,001)$ com gordura do pernil $(\mathrm{r}=0,85)$ e do lombo $(r=0,71)$. Ainda foi observada correlação significativa positiva $(\mathrm{P}<0,01)$ entre gordura do pernil $(\mathrm{r}=0,90)$ e do lombo $(r=0,90)$ com o estado de engorduramento da carcaça, avaliado subjetivamente. Ribeiro et al. (2009a) já havia relatado menor valor para conformação $(2,5)$ e estado de engorduramento da carcaça $(1,12)$ dos cordeiros desmamados e terminados em pasto em relação aos demais sistemas (3,1 e 2,8), os quais presente trabalho apresentaram inferior espessura mínima e máxima de gordura de cobertura no lombo.

A relação músculo:gordura no lombo e no pernil foram maiores $(\mathrm{P}<0,05)$ para os cordeiros desmamados com dieta exclusiva em pasto. Isso se deve à menor deposição de gordura no pernil. O índice de musculosidade, indicador da quantidade de músculo em relação ao comprimento do corte, foi menor $(\mathrm{P}<0,05)$ para os cordeiros desmamados em pasto em relação aos cordeiros terminados com suas mães e confinados.

Tabela 5 - Total de ácidos graxos (g/100 g de carne) e percentuais (\%) de ácidos graxos saturados, monoinsaturados e poliinsaturados no lombo de cordeiros em diferentes sistemas de terminação

\begin{tabular}{|c|c|c|c|c|c|}
\hline \multirow[b]{2}{*}{ Ácidos graxos $^{1}$} & \multicolumn{4}{|c|}{ Sistema de terminação } & \multirow{2}{*}{$\begin{array}{l}\text { Erro-padrão } \\
\text { da média }\end{array}$} \\
\hline & Pastagem & $\begin{array}{l}\text { Pastagem } \\
\text { mãe }\end{array}$ & $\begin{array}{c}\text { Pastagem }+ \text { creep } \\
\text { feeding }+ \text { mãe }\end{array}$ & Confinamento & \\
\hline Ácidos graxos totais & $5,93 b$ & $13,81 \mathrm{ab}$ & $16,44 a$ & $12,30 \mathrm{ab}$ & 2,49 \\
\hline Saturados & 51,88 & 55,99 & 51,96 & 57,98 & 5,85 \\
\hline C14:0 & 7,72 & 7,37 & 6,31 & 8,57 & 3,00 \\
\hline C16:0 & 32,73 & 26,49 & 26,41 & 26,50 & 2,01 \\
\hline C18:0 & $9,39 b$ & $22,29 a$ & $18,60 \mathrm{ab}$ & $18,01 \mathrm{ab}$ & 3,09 \\
\hline C20:0 & $0,22 b$ & $0,36 a b$ & 0,96a & $0,08 b$ & 0,19 \\
\hline Monoinsaturados & 32,50 & 34,48 & 36,89 & 33,51 & 2,40 \\
\hline $\mathrm{C} 16: 1 \omega 7$ & $1,10 \mathrm{a}$ & $0,50 \mathrm{~b}$ & $0,54 b$ & $0,07 c$ & 0,12 \\
\hline 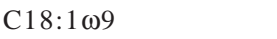 & 27,63 & 35,08 & 36,35 & 34,54 & 4,48 \\
\hline Poliinsaturados & 4,70 & 2,11 & 5,20 & 1,94 & 0,25 \\
\hline $\mathrm{C} 18: 2 \omega 6$ & 1,36 & 1,62 & 4,86 & 2,04 & 1,87 \\
\hline 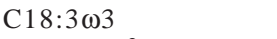 & $0,14 \mathrm{bc}$ & $0,41 \mathrm{a}$ & $0,36 a b$ & $0,08 \mathrm{c}$ & 0,05 \\
\hline AGP:AGS ${ }^{2}$ & 0,10 & 0,04 & 0,10 & 0,04 & 0,03 \\
\hline
\end{tabular}

Médias seguidas por letras distintas nas linhas diferem $(\mathrm{P}<0,05)$ entre si pelo teste Tukey.

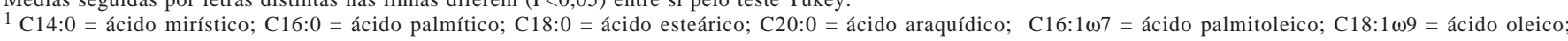

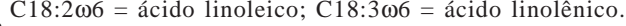

2 AGP:AGS = total de ácidos graxos poliinsaturados/total de ácidos graxos saturados . 
Cordeiros com suas mães em pasto de azevém em creep feeding apresentaram mais $(\mathrm{P}<0,05)$ ácidos graxos na carne que cordeiros desmamados no pasto. Portanto, a ingestão de leite materno mais a suplementação promoveram esse resultado.

French et al. (2000) estudaram o perfil de ácidos graxos de bovinos terminados com dietas a base de forragem, silagem ou concentrado. Os animais consumindo exclusivamente pastos de gramíneas apresentaram menores teores de ácidos graxos saturados e os teores de ácidos graxos insaturados aumentaram. No presente trabalho não foi observado $(\mathrm{P}>0,05)$ efeito do sistema de terminação sobre o percentual deácidos graxos saturados, monoinsaturados e poliinsaturados. Os ácidos graxos C6:0, C8:0, C10:0, C12:0, C14:0, C22:0, C18:1 trans 9 eram menores que $0,01 \%$ e, por isso, não foram considerados.

Ao avaliar o efeito do concentrado no período de terminação dos animais é preciso considerar a influência da sua duração. Noci et al. (2005) estudaram o efeito do tempo de terminação (0, 44, 99 e 158 dias) em pastagem de azevém sobre o perfil de ácidos graxos da carne de bovinos. Nesse caso, o aumento no tempo de terminação em pasto promoveu acréscimo linear no percentual de ácidos graxos poliinsaturados e da relação poliinsaturados:saturados e redução linear no percentual de ácidos graxos saturados na carne. Duckett et al. (1993) estudaram o efeito do tempo de alimentação (0, 28, 56, 84, 112, 140, 168 e 196 dias) concentrada na qualidade da carne de bovinos. Os autores observaram aumento cúbico no percentual de ácidos graxos saturados com pico de concentração aos 56 dias. Os ácidos graxos monoinsaturados apresentaram aumento linear de $22 \%$ e os poliinsaturados, efeito quadrático durante o período de avaliação com redução de $72 \%$ entre 0 e 196 dias.

No presente trabalho, provavelmente o tempo de permanência nos sistemas (118 dias, cordeiros desmamados em pasto; 65 dias, cordeiros com suas mães em pasto; 66 dias, cordeiros em creep feeding; e 56 dias, cordeiros confinados) mais a baixa proporção de concentrado em relação ao volumoso nas dietas não foram suficientes para alterar os percentuais de ácidos graxos. Portanto, devido ao curto período de terminação dos cordeiros, a alimentação não teve efeito na qualidade da carne para o consumo humano, quanto a esse aspecto.

Entre os ácidos identificados na gordura intramuscular, houve predominância de cinco (ácido mirístico, C14:0; ácido palmítico, C16:0; ácido esteárico, C18:0; ácido oleico,

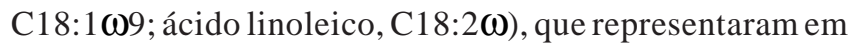
média $88 \%$ do total, sendo que apenas o ácido esteárico (C18:0) foi influenciado $(\mathrm{P}<0,05)$ pelas diferentes dietas. $\mathrm{O}$ ácido oleico (C18:1 $\omega 9)$ foi o ácido graxo insaturado que mais contribuiu para a composição total dos ácidos, enquanto os ácidos palmítico (C16:0) e esteárico (C18:0) contribuíram mais entre os saturados. Resultado semelhante foi observado por Ferrão et al. (2009), avaliando diferentes relações de forragem — concentrado(100:0, 75:25 e 50:50)—,e Fernandes (2008), com cordeiros desmamados em pasto com suplementação concentrada (0, 1 e 2\% do PV e ad libitum).

Entre os ácidos graxos saturados, apenas o esteárico (C18:0) e o araquídico (C20:0) foram influenciados $(\mathrm{P}<0,05)$ pelo sistema de terminação. Cordeiros terminados ao pé das mães sem suplementação apresentaram maiores $(\mathrm{P}<0,05)$ percentuais de ácido esteárico que os desmamados. Segundo Novello et al. (2008), o ácido esteárico, ao contrário de outros ácidos graxos saturados, classifica-se como não aterogênico (neutro). Nesse caso, o aumento deste nos animais não desmamados e sem suplementação não pode ser considerado como fator prejudicial da carne para o consumo humano.

Os ácidos graxos mono e poliinsaturados são considerados benéficos à saúde humana. Segundo Cooper et al. (2004), a dieta pode alterar a porcentagem de ácido

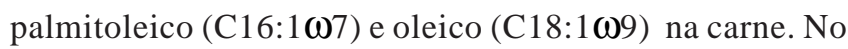
presente trabalho, os animais confinados apresentaram menores $(\mathrm{P}<0,05)$ percentuais de ácido oleico na carne que cordeiros terminados em azevém. Estes, por sua vez, apresentaram maiores teores de ácido oleico que cordeiros não desmamados, com ou sem suplementação. No entanto, Fisher et al. (2000) e Velasco et al. (2004) observaram maior porcentagem de ácido oleico para dietas com cereais comparadas com os cordeiros em pasto.

Trabalhos mostram que há diferença em ácidos graxos da carne de cordeiros em amamentação e desmamados. Bas \& Morand-Fehr (2000) observaram baixa proporção de ácido esteárico (C18:0), linoleico (C18:2) e linolênico(C18:3) e alta porcentagem de ácido mirístico (C14:0), palmítico (C16:0) e oleico(C18:1)na carne de cordeiros não desmamados. O leite é rico em C14:0 e C16:0. Depois da desmama, a porcentagem de C14:0 gradualmente diminui e a porcentagem de ácidos graxos saturados de cadeia longa aumenta. Provavelmente, isso resulta da menor porcentagem de ácidos graxos de cadeias curta e média e da alta porcentagem de ácidos de cadeia longa da dieta pós-desmame. Tal fato foi confirmado apenas para o percentual de ácido linolênico (C18:3(13), sendo que cordeiros sem desmame e sem suplementação apresentaram maiores $(\mathrm{P}<0,05)$ percentuais que os cordeiros desmamados em pasto ou confinados.

A avaliação iniciou após quatro semanas de lactação. Segundo Garcia et al. (2003), o pico da produção de leite ocorre entre a $3^{\mathrm{a}}$ e a $4^{\mathrm{a}}$ semana após o parto, considerando-se que $75 \%$ do total da lactação é produzida nas primeiras oito semanas. Provavelmente, a ingestão de leite materno não 
foi suficiente para promover mudanças nos percentuais dos ácidos graxos mirístico (C14:0) e palmítico (C16:0).

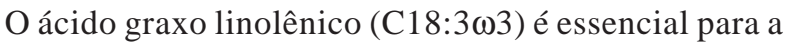
saúde humana, porém apresenta menor ponto de fusão e maior risco de peroxidação da gordura em virtude da instabilidade das ligações duplas do mesmo (Cifune et al., 2000). Entretanto, o efeito negativo da peroxidação só ocorre na presença de grande quantidade desse ácido. Segundo Díaz et al. (2002), como consequência do alto teor do ácido linolênico nas pastagens, normalmente os animais apresentam maiores teores na carne. Nos sistemas em pasto de azevém, a carne apresentou maior teor de ácido linolênico em relação à carne dos terminados em confinamento, o que também foi observado por Fisher et al. (2000) e Díaz et al. (2002).

Segundo Wood et al. (2003), o Ministério da Saúde do Reino Unido recomenda a relação entre ácidos graxos poliinsaturados e saturados (AGP:AGS) dos alimentos maior que 0,4 , visando evitar doenças associadas ao consumo de gorduras saturadas. No entanto, segundo Scollan et al. (2001), a relação entre os ácidos graxos poliinsaturados/saturados (AGP:AGS) na carne geralmenteébaixa, ao redor de 0,1 , exceto para animais muito magros ( $<1 \%$ de gordura intramuscular) e com o dobro de tecido muscular, nos quais a relação AGP:AGS é de aproximadamente 0,5-0,7. Em geral, a manipulação nutricional não eleva a relação AGP:AGS acima do normal, variando entre 0,06-0,15 devido ao alto grau de biohidrogenação dos poliinsaturados dietéticos no rúmen (Scollan et al., 2005). De maneira geral, os valores médios encontrados $(0,07)$ foram baixos, embora dentro do citado por Scollan et al. (2001).

É importante ressaltar que nem todos os ácidos graxos saturados são considerados hipercolesterolêmicos (que aumentam o colesterol ruim — LDL). French et al. (2003) relataram que o ácido graxo mais indesejável seria o mirístico (C14:0), que neste estudo representou apenas 7,5\% do total dos ácidos. O ácido palmítico (C16:0), que apresentou média de 29,4\%, é citado como o de menor efeito hipercolesterolêmico. No caso do ácido esteárico (C18:0), média de 17,7\% do total, ele tem efeito nulo, pois se transforma em ácido oleico (C18:1) no organismo (Sinclair, 1993), não influenciando nos níveis sanguíneos de colesterol. Portanto, do total de ácidos graxos observados na carne dos cordeiros (Tabela 5), apenas 36,9\% são considerados prejudiciais à saúde.

A ingestão de ácidos graxos saturados eleva o colesterol sérico em humanos (Ewin, 1997). Contudo, quando é substituída por monoinsaturados, os níveis de colesterol total no plasma sanguíneo diminuem (Department of Health, 1994). Do total de ácidos graxos na carne dos cordeiros, 34,5\% foram monoinsaturados, com ácido oleico em 97\% do total. O ácido oleico é desejável por ter ação hipocolesterolêmica, com a vantagem de não reduzir o colesterol HDL, atuando na proteção contra doenças coronarianas.

\section{Conclusões}

O desmame de cordeiros em terminação em pastagem de azevém aos 40 dias de idade limita o desenvolvimento muscular desses animais e reduz a deposição de gordura nas carcaças, confirmando que a presença da mãe é importante para os animais atingirem composição tecidual próxima a de cordeiros terminados em confinamento. $\mathrm{O}$ confinamento de cordeiros desmamados com alimentação de boa qualidade pode ser uma possibilidade de compensação do desmame, evidenciada pelo bom desenvolvimento muscular e pela adequada deposição de gordura na carcaça. A presença da mãe, associada à suplementação em creep feeding, resulta em maior teor de ácidos graxos na carne. No entanto, os sistemas de terminação não afetam o percentual de ácidos graxos saturados, monoinsaturados e poliinsaturados da carne.

\section{Agradecimentos}

Ao Conselho Nacional de Desenvolvimento Científico e Tecnológico (CNPq), pelo apoio financeiro ao projeto de pesquisa e pela bolsa de mestrado concedida à quarta autora. À Coordenação de Aperfeiçoamento Pessoal de Ensino Superior (CAPES), pelas bolsas de mestrado concedidas à primeira e à sexta autora deste trabalho.

\section{Referências}

ANDRADE, J.G.; DUCKETT, S.K.; HUNT, C.W. et al. Effects of feeding high-oil corn to beef steers on carcass characteristics and meat quality. Journal of Animal Science, v.79, p.582-588, 2001. Disponível em: <http://www.animal-science.org/cgi/reprint/ 79/3/582.pdf> Acesso em: 20/4/2007.

BAS, P.; MORAND-FER, P. Effect of nutritional factors on fatty acid composition of lamb fat deposits. Livestock Production Science, v.64, p.61-79, 2000.

BROWN, A.J.; WILLIANS, D.R. Sheep carcass evaluation: measurement of composition using a standardised butchery method. Langford: Agricultural Research Council, Meat Research Council, 1979. 16p. (Memorandum, 38).

BUENO, M.S.; CUNHA, E.A.; SANTOS, L.E. et al. Características de carcaça de cordeiros Suffolk abatidos em diferentes idades. Revista Brasileira de Zootecnia, v.29, n.6, p.1803-1810, 2000. Disponível em: <http://www.scielo.br/pdf/rbz/v29n6/ 5712.pdf> Acesso em: 14/3/2007.

CAÑEQUE, V.; HUIDOBRO, F.R.; DOLZ, J.F. La canal de cordero. In: PRODUCCIÓN DE CARNE DE CORDERO, 1992, México. Anais... México: Ministério de Agricultura, Pesca y Alimentación, 1992. p.367-436. 
CARVALHO, P.C.F. Manejando pastagens para ovinos. In: PEREIRA NETO, O.A.; MÓRLAN, J.B.; CARVALHO, P.C.F. et al. (Eds.) Práticas em Ovinocultura - Ferramentas para o sucesso. Porto Alegre: SENAR, 2004. p.15-28.

CIFUNE, G.F.; NAPOLITANO, F.; PACELLI, C. et al. Effect of age at slaughter on carcass traits, fatty acid composition and lipid oxidation of Apulian lambs. Small Ruminant Research, v.35, p.65-70, 2000

COLOMER-ROCHER, F. Estúdio de los parâmetros que definem los caracteres cuantitativos y cualitativos de las canales. In: CURSO INTERNACIONAL SOBRE PRODUCCIÓN DE CARNE Y LECHE CON BASES EM PASTOS Y FORRAGES. La Coruña. Anais... LaCoruña, Espana: 1988. p.108.

COOPER, S.L.; SINCLAIR, L.A.; WILKINSON, R.G. et al. Manipulation of the $n-3$ polyunsaturated fatty acid content of muscle and adipose tissue in lambs. Journal of Animal Science, v.82, p.1461-1470, 2004. Disponível em: <http:// jas.fass.org/cgi/content/full/82/5/1461> Acesso em: 20/4/2007.

DEPARTMENT OF HEALTH. Report on health and social subjects $\mathrm{n}^{\circ}$ 46. Nutritional Aspects of Cardiovascular Disease. London: HMSO, 1994. p.178.

DÍAZ, M.T.; VELASCO, S.; CAÑEQUE, V. et al. Use of concentrate or pasture for fattening lambs and its effect on carcass and meat quality. Small Ruminant Research, v.43, p.257-268, 2002.

DUCKETT, S.K.; WAGNER, D.G.; YATES, L.D. et al. Effects of time on feed on beef nutrient composition. Journal of Animal Science, v.71, p.2079-2088, 1993. Disponível em: <http:// jas.fass.org/cgi/reprint/71/8/2079.pdf> Acesso em: 15/06/2009.

EUCLIDES, V.P.B.; MACEDO, M.C.M.; OLIVEIRA, M.P. Avaliação de diferentes métodos de amostragem sob pastejo. Revista Brasileira de Zootecnia, v.21, n.4, p.691-702, 1992.

EWIN, J. O lado sadio das gorduras. Tradução de Ana Beatriz Rodrigues. Rio de Janeiro: Campus Ltda., 1997. p.162.

FERNANDES, M.A.M.; MONTEIRO, A.L.G.M.; POLI, C.H.E.C. et al. Características do lombo e cortes da carcaça de cordeiros Suffolk terminados em pasto e confinamento. Boletim da Industria Animal, v.65, n.2, p.107-113, 2008. Disponível em: <http:// www.iz.sp.gov.br/bia.php?vol=65\&num_vol=2> Acesso em 5/5/2008.

FERRÃO, S.P.B.; BRESSAN, M.C.; OLIVEIRA, R.P. et al. Características sensoriais da carne de cordeiros da raça Santa Inês submetidos a diferentes dietas. Ciências e Agrotecnologia, v.33, n.1, 2009. Disponível em: <http://www.scielo.br/scielo.php? script=sci_arttext\&pid=S1413-70542009000100026\&lng=en\&nrm= iso\&tlng $=$ pt $>$. Acesso em: 24/5/2010.

FISHER, A.V.; ENSER, M.; RICHARDSON, R.L. et al. Fatty acid composition and eating quality of lamb types derived from four diverse breed x production systems. Meat Science, v.55, p.141-147, 2000.

FRENCH, P.; O’RIORDAN, E.G.; MONAHAN, F.J. et al. Fatty acid composition of intra-muscular triacylglycerols of steers fed autumn grass and concentrates. Livestock Production Science, v.81, p.307-317, 2003.

FRENCH, P.; O’RIORDAN, E.G.; MONAHAN, F.J. et al. Meat quality of steers finished on autumn grass, grass silage or concentrate-based diets. Meat Science, v.56, p.173-180, 2000.

GARCIA, C.A.; COSTA, C.; MONTEIRO, A.L.G. et al. Níveis de energia no desempenho e características da carcaça de cordeiros alimentados em creep feeding Revista Brasileira de Zootecnia, v.32, n.6, p.1371-1379, 2003. Disponível em: <http:// www.scielo.br/pdf/rbz/v32n6/18426.pdf $>$. Acesso em 24/05/2010.

GONZAGA NETO, S.; SILVA SOBRINHO, A.G.; ZEOLA, N.M.B.L. et al. Características quantitativas da carcaça de cordeiros deslanados Morada Nova em função da relação volumoso: concentrado na dieta. Revista Brasileira de Zootecnia, v.35, n.4, p.1487-1495, 2006. Disponível em: <http://www.iz.sp.gov.br/ bia.php?vol=65\&num_vol=2> Acesso em: 5/5/2008.

HARTMAN, N.L.; LAGO, R.C. A rapid preparation of fatty acid methyl esters from lipids. Laboratory pratice, v.22, n.9, p.475-476, 1973.
HASLER, C.M. Functional foods: their role in disease prevention and health promotion. Food Technology, v.52, p.57-62, 1998.

HUIDOBRO, F.R.; CAÑEQUE, V. Producción de carne de corderos de raza Manchega. 5. Crescimento relativo del quarto y de los tejidos y piezas e la canal. Investigación y Sanidad Animales, n.2, v.9, p.95-108, 1994.

KEARL, L.C. Nutrient requirements of ruminants in developing countries. Utah: International Feedstuffs Institute, Utah Agricultural Experiment Station, Utah State University, 1982. 380p.

LUCHIARI FILHO, A. Pecuária da carne bovina. 1.ed. São Paulo: A. Luchiari Filho, 2000. p.134.

MOTT, G.O.; LUCAS, H.L. The design, conduct and interpretation of grazing trials on cultivated and improved pastures. In: INTERNATIONAL GRASSLAND CONGREES, 6., 1952, State College. Proceedings... State College: Pensylvania State College Press, 1952. p.1380-1385.

NOVELLO, D.; FRANCESCHINI, P.; QUINTILIANO, D.A. A importância dos ácidos graxos $\omega$-3 e $\omega$-6 para a prevenção de doenças e na saúde humana. Revista Salus, v.2, n.1, p.77-87, 2008. Disponível em: <http://revistas.unicentro.br/index.php/ salus/ article/view/694/825>. Acesso em: 25/5/2010.

NOCI, F.F.; MNAHAN, F.J.; FRENCH, P. et al. The fatty acid composition of muscle fat and subcutaneous adipose tissue of pasture-fed beef heifers: influence of the duration of grazing. Journal of Animal Science, v.83, p.1167-1178, 2005. Disponível em: <http://jas.fass.org/cgi/content/full/83/5/1167>. Acesso em: 15/3/2007.

NATIONAL RESEARCH COUNCIL - NRC. Nutrient requirements of sheep. Washington, D.C.: National Academy Press, 1985.

OSÓRIO, J.C.S.; OSÓRIO, M.T.M.; OLIVEIRA, N.R.M. et al. Qualidade, morfologia e avaliação de carcaças. Pelotas: Editora e Gráfica Universitária - UFPel, 2002. 196p.

PURCHAS, R.W.; DAVIES, A.S.; ABDULLAH, A.Y. An objective measure of muscularity: changes with animal growth and differences between genetic lines of Southdown sheep. Meat Science, v.30, p.81-94, 1991.

RIBEIRO, T.M.D.; MONTEIRO, A.L.G.; PRADO, O.R. et al. Desempenho animal e características das carcaças de cordeiros em quatro sistemas de produção. Revista Brasileira de Saúde Produção Animal, v.10, n.2, p.366-378, 2009a. Disponível em: <http://www.rbspa.ufba.br/index.php/rbspa/ article/view/1240/837>. Acesso em: 24/5/2010.

RIBEIRO, T.M.D.; MONTEIRO, A.L.G.; POLI, C.E.C.. et al. Características da pastagem de azevém e produtividade de cordeiros em pastejo. Revista Brasileira de Zootecnia, v.38, n.3, p.580-587, 2009b. Disponível em: <http://www.scielo.br/pdf/rbz/v38n3/ a25v38n3.pdf $>$. Acesso em 24/5/2010.

ROSA, G.T.; PIRES, C.C.; SILVA, J.H. et al. Composição tecidual da carcaça e de seus cortes e crescimento alométrico do osso, músculo e gordura da carcaça de cordeiros da raça texel. Acta Scientiarum Animal Science, v.24, n.4, p.1107-1111, 2002. Disponível em: <http://www.periodicos.uem.br/ojs/index.php/ ActaSciAnimSci/article/view/2534/1753 >. Acesso em: 24/5/2010.

SAINZ, R.D. Produção, qualidade e comercialização de carnes. Ribeirão Preto: Universidade de São Paulo, 1996. p.14.

SANTOS-SILVA, J.; MENDES, I.A.; BESSA, R.J.B. Effect of genotype, feeding system and sloughter weight on the quality of light lambs. I. Growth, carcass composition and meat quality. Livestock Production Science, v.76, p.17-25, 2002

SAÑUDO, C.; SIERRA, I. Calidad de la canal en la especie ovina. Ovino, v.1, p.127-153, 1986.

SAS. Institute System for Information. Versão 6.11, Carry, 2001. Disquete 3.5 '.

SCOLLAN, N.D.; CHOI, N.J.; KURT, E. et al. Manipulating the fatty acid composition of muscle and adipose tissue in beef cattle. British Journal of Nutrition, v.85, p.115-124, 2001. Disponível em: <http://journals.cambridge.org/download.php?file= 2FBJN\%2FBJN85_01\%2FS0007114501000150a.pdf\&code= 17938ace0ba3e1bcb810d4d41529542f > . Acesso em: 2/9/2006. 
SCOLLAN, N.D.; DEWHURST, R.J.; MOLONEY, A.P. et al. Improving the quality of products from grassland. In: INTERNATIONAL GRASSLAND CONGRESS, 23., 2005, Dublin. Proceedings... Dublin: International Grassland Congress, 2005. p.41-56.

SILVA, D.J. Análise de alimentos (métodos químicos e biológicos). 2.ed. Viçosa, MG: Universidade Federal de Viçosa. 1990. p. 256.

SINCLAIR, A.J. Dietary fat and cardiovascular disease: the significance of recent developments for the food industry. Food Australia, v.45, p.226, 1993.
SIQUEIRA, E.R.; FERNANDES, S. Efeito do genótipo sobre as medidas objetivas e subjetivas da carcaça de cordeiros terminados em confinamento. Revista Brasileira de Zootecnia, v.29, n.1, p.306-311, 2000. Disponível em: <http://www.scielo.br/ pdf/rbz/v29n1/5763.pdf > Acesso em: 15/3/2007.

VELASCO, S.; CAÑEQUE, V.; LAUZURICA, S. et al. Effect of different feeds on meat quality and fatty acid composition of lambs fattened at pasture. Meat Science, v.66, p.457-465, 2004. WOOD, J.D.; RICHARDSON, R.I.; NUTE, G.R. et al. Effects of fatty acids on meat quality: a review. Meat Science, v.66, p.21-32, 2003. 